\title{
Aproveitamento do caulim e proposta para recuperação da área minerada no Sítio
}

\section{Galo Branco, Equador, RN}

\author{
Use of kaolin and proposal to recover the mined area at Sítio Galo Branco, Ecuador, RN \\ Uso de caolín y propuesta de recuperación del área minada en Sítio Galo Branco, Ecuador, RN
}

\section{Resumo}

Este artigo tem por objetivo apresentar alguns aspectos importantes do aproveitamento do caulim no Sítio Galo Branco, localizado em Equador, RN, no Seridó, e uma proposta para a recuperação da área minerada. Além disso, apresentar uma abordagem sobre os riscos que ocorrem no processo de extração do caulim, as condições de saúde e segurança no trabalho, os impactos gerados pelas práticas inadequadas utilizadas e sugerir ações para a melhoria do desempenho técnico, ambiental e socioeconômico dessa atividade. Para tanto, como procedimento metodológico, foi realizado uma revisão da literatura existente que aborda a temática em estudo, juntamente com visitas técnicas à região. Por fim, recomenda-se a necessidade de uma política pública eficaz e eficiente de apoio aos micros e pequenos mineradores da região, assim como ações de recuperação de áreas degradadas.

Palavras-chave: Caulim; Equador; Recuperação de Áreas.

\begin{abstract}
This article aims to present some important aspects of the use of kaolin at Sítio Galo Branco, located in Ecuador, RN, in Seridó, and a proposal for the recovery of the mined area. In addition, to present an approach on the risks that occur in the process of extracting kaolin, the health and safety conditions at work, the impacts generated by the inappropriate practices used and to suggest actions to improve the technical, environmental and socioeconomic performance of this activity. Therefore, as a methodological procedure, a review of the existing literature was carried out that addresses the subject under study, together with technical visits to the region. Finally, it is recommended the need for an effective and efficient public policy to support micro and small miners in the region, as well as actions to recover degraded areas.
\end{abstract}

Keywords: Kaolin; Ecuador; Area Recovery. 


\section{Resumen}

Este artículo tiene como objetivo presentar algunos aspectos importantes del uso del caolín en el Sítio Galo Branco, ubicado en Ecuador, RN, en Seridó, y una propuesta para la recuperación del área minada. Además, presentar un acercamiento a los riesgos que se presentan en el proceso de extracción del caolín, las condiciones de salud y seguridad en el trabajo, los impactos generados por las prácticas inadecuadas utilizadas y sugerir acciones para mejorar el desempeño técnico, ambiental y socioeconómico de esta actividad. Por lo tanto, como procedimiento metodológico, se realizó una revisión de la literatura existente que aborda el tema en estudio, junto con visitas técnicas a la región. Finalmente, recomendamos la necesidad de una política pública eficaz y eficiente de apoyo a la micro y pequeña minería de la región, así como acciones de recuperación de áreas degradadas.

Palabras clave: Caolín; Ecuador; Área de recuperación

\section{Introdução}

A Mineração é uma atividade econômica importante e que atende as demandas da sociedade, fornecendo insumos para setores como: indústria metalúrgica, siderúrgica, química, cerâmica, construção civil, dentre outros. Segundo Almeida (2010), mesmo cercado por muita crítica, e apesar de, historicamente, a ocupação e uso do solo em busca de riquezas minerais tenha ocorrido de forma pontual no Brasil (Resende, 2002), este setor é grande indutor de geração de emprego e renda, principalmente o segmento de micros e pequenas empresas, que desenvolvem suas operações mineiras em territórios de grande vulnerabilidade social e ambiental.

As críticas decorrem do fato de ser uma atividade geradora de impacto ambiental de grau elevado, que vão desde efeitos consideráveis na flora e fauna, até a poluição da água, do ar e a degradação do solo.

Esse quadro de alerta leva a necessidade de inserção de ações de planejamento para a recuperação dessas áreas, com ações de fertilização e plantio de espécies nativas da região, que permitam a reabilitação da paisagem degradada. Entretanto, é importante salientar que no processo de recuperação a ser adotado, dever ser observada a escolha de espécies a serem plantadas, de modo a considerar a presença de biomassa de carbono microbiano, parâmetro que reflete características qualitativas do solo, e que pode se apresentar em áreas degradadas aquém dos valores normalmente encontrados em solos não degradados.

A recuperação progressiva de áreas degradadas consiste na implantação de medidas de reabilitação durante a fase de operação da mina, em paralelo com as operações de lavra. Esse modelo de recuperação pode incluir ações como a reposição do solo superficial, a instalação de cinturão verde ou cortina arbórea, o plantio de vegetação em taludes e bermas de pilhas de estéril, a recomposição de vegetação nativa em margens de rios e em áreas desmatadas. (Sánchez, et al., 2013).

A respeito do tema degradação, convém ressaltar aspectos peculiares da atividade extrativa de minerais sob a ótica positivista na região de estudo, onde foram observados também aspectos sociais, econômicos, ambientais e técnicos para a elaboração de uma proposta de recuperação da área degradada por essa atividade.

A extração de caulim é intensa na Província Pegmatítica Borborema/Seridó, localizada entre os estados do Rio Grande do Norte e da Paraíba. Essa Província é reconhecida como uma das mais importantes do país pelas suas peculiaridades e diversidade de substâncias minerais existentes em seu subsolo, tais como feldspato, mica, quartzo, caulim, tantalita/columbita, gemas, quartzitos, dentre outras (Sousa et al., 2018) e por isso, tem sido muito pesquisada e estudada por cientistas e especialistas da Geociências.

Segundo informações de pequenos mineradores da região, as operações de lavra, ou extração do caulim, ocorrem nos municípios de Junco do Seridó, PB, e Equador, RN, desde 1953, e foram intensificadas com a criação da Reserva Garimpeira do Seridó, pela Portaria do MME $\mathrm{n}^{\circ}$ 1.524, de 27/10/1982, que destinou a área de 35.563, 29 ha para o aproveitamento dos minerais garimpáveis nesses municípios e na Província Pegmatítica da Borborema, de modo a gerar emprego, renda e minimizar efeitos da estiagem prolongada na região. 
Numa área denominada Sítio Galo Branco, há uma área mineralizada de caulim, em processo de formalização, que necessita de acompanhamento especializado para que as operações de lavra sejam desenvolvidas, de modo a reduzir os impactos ambientais e, ao mesmo tempo, seja implantado um plano de recuperação da área degradada, de acordo com o que estabelece a legislação ambiental em vigor, onde é exigido que os empreendimentos minerários, que extraem e aproveitam recursos minerais, devem elaborar e apresentar ao órgão ambiental competente um Plano de Recuperação de Área Degradada PRAD, prevendo o uso sequencial da área minerada e sua reabilitação.

Este artigo descreve estudos realizados numa área da mesorregião do Seridó, onde foi possível observar os impactos gerados pelo aproveitamento desordenado do caulim, sob os aspectos técnicos, ambiental, social e econômico. A partir do diagnóstico embasado em revisão de literatura e visitas técnicas, foi proposta uma metodologia de aproveitamento dessa substância mineral de forma mais racional e sustentável. Além disso, foi apresentado um plano de recuperação da área minerada, com o uso de espécies nativas do Bioma Caatinga, como forma de contribuir para a reabilitação da área degradada e atender as exigências da legislação ambiental vigente.

\section{Materiais e Métodos}

\subsection{Localização}

A área objeto desse estudo está localizada próxima ao município de Equador e inserida na mesorregião Central Potiguar e na microrregião do Seridó Oriental. O município possui uma área de $312 \mathrm{~km}^{2}$, distando $283 \mathrm{~km}$ de Natal, capital do Rio Grande do Norte (CPRM, 2005), e a cerca de 110 km de Campina Grande, Paraíba, cuja rodovia de acesso é a BR 230.

O município de Equador limita-se ao norte com o município de Parelhas, RN, ao sul, leste e oeste com os municípios paraibanos: Junco do Seridó e Tenório. Àquele povoado possui altitude média de $572 \mathrm{~m}$ e situa-se nas coordenadas $06^{\circ} 56^{\prime} 42^{\text {" }}$ de latitude Sul e $36^{\circ} 43^{\prime} 04^{\prime \prime}$ de longitude oeste (CPRM, 2005). (Figura 1).

Figura 1 - Mapa de localização da área de estudo.
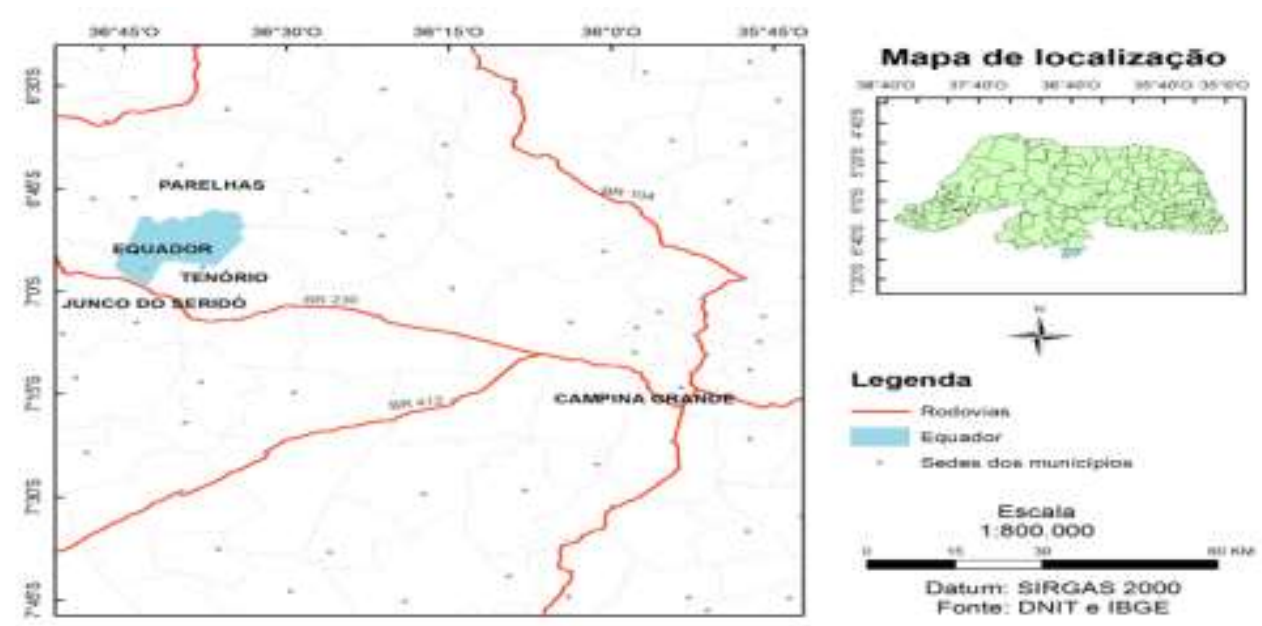

Fonte: DNIT e IBGE (2016).

\subsection{Aspectos Técnicos e Legais da Recuperação da Área Minerada}

Conforme citado anteriormente, os processos de extração mineral promovem a degradação do solo e atualmente, diante do desafio de mineração sustentável, o processo de revegetação e reabilitação deve ser um desafio a ser encarado com 
estudos contínuos e saberes interdisciplinares a fim de aplicar o conhecimento necessário para alcançar a tarefa complexa de sucesso na recuperação destas áreas.

Inicialmente, mudanças estruturais e funcionais podem ser encontradas, dentro deste cenário e daí a necessidade de estudos interdisciplinares de modo a comparar os resultados alcançados em outros cenários. Estudos realizados sobre as espécies que podem ser aplicadas em revegetação de minas podem ser bastante úteis.

Um estudo realizado por Gastauer et al (2018) apresentou como ferramentas poderosas as abordagens funcionais e filogenéticas modernas em ecologia de comunidade, uma vez que permitem aprimorar todo o processo de reabilitação e superar esses desafios. No entanto, o mesmo trabalho especifica que metodologias que incorporam informações filogenéticas atualizadas ou conhecimento sobre variações intraespecíficas ao longo das trajetórias de reabilitação devem ser desenvolvidas, com uso de ferramentas adicionais, como sensoriamento remoto, para enriquecer os aspectos de manejo com fins de uma mineração mais sustentável.

Os estudos realizados por Harantová et al (2017), por sua vez, ressaltam outro aspecto que enfatiza a importância da interdisciplinaridade da prática de reabilitação de áreas degradadas por atividades de mineração. Este trabalho verificou que ecossistemas florestais complexos se desenvolveram ao longo de 54 anos no solo originalmente estéril de zona temperada. Isto indicou a importância das bactérias na fase inicial de desenvolvimento do solo, e, embora a chegada da vegetação tenha afetado as comunidades de fungos e bactérias, foram principalmente os fungos que responderam bem ao desenvolvimento contínuo da vegetação numa área de depósito de entulho de uma mina de carvão marrom na República Tcheca.

A legalização ou a formalização das atividades de extração mineral é um passo importante para a reabilitação ambiental, uma vez que permite fazer uma caracterização mais detalhada sobre as reais circunstâncias do ambiente degradado. Por conseguinte, programas de apoio à legalização de áreas de jazidas minerais podem ser encontrados na literatura vigente. Ferreira et al (2012) desenvolveram um projeto com objetivo de orientar tecnicamente as atividades de caracterização, de planejamento e de extração de matérias-primas argilosas das jazidas minerais de Rio Claro. Na segunda etapa desse projeto, foi elaborado um plano para a recuperação de áreas de preservação permanente, afetadas e degradadas por antigas extrações de argila, ocorridas nas várzeas dos cursos de água, para alimentar as operações de quatorze olarias.

A legislação ambiental vigente determina que o objetivo da recuperação da área é propiciar um novo equilíbrio dinâmico, com o desenvolvimento de um novo solo e de uma nova paisagem (TAVARES, 2008).

Os Planos de Recuperação de Áreas Degradadas - PRADs representam a descrição formal das propostas de soluções técnicas de recuperação definidas pelas empresas de mineração, conforme estabelece a legislação ambiental brasileira, sendo elementos básicos para monitoramento e avaliação dos aspectos principais do planejamento da recuperação.

De acordo com Bitar (1997), as atividades de recuperação envolvem a avaliação das áreas degradadas; o planejamento da recuperação; o desenvolvimento de métodos e técnicas de recuperação; a adoção de medidas geotécnicas; a realização do monitoramento e manutenção da área. Essas atividades são importantes na reabilitação ecológica de áreas de mineração visto que, dependendo das características da exploração do solo, algumas espécies de plantas terão maior ou menor grau de resistência às características e ao grau de sua degradação.

Em 2005, o Governo Federal estimulou a criação dos Arranjos Produtivos Locais de Base Mineral - APLs, com a finalidade de impulsionar o desenvolvimento de cadeias produtivas minerais, especialmente de micro e pequeno porte, reunidas em aglomerações no mesmo espaço geográfico.

A partir desses estudos, foi constituído o APL de Pegmatitos RN/PB, com o propósito de conscientizar os micros e pequenos mineradores à adoção de práticas mais racionais e responsáveis nas operações de lavra, de beneficiamento e de comercialização dos minérios, visando à inserção de princípios de sustentabilidade na região. 
A Província Pegmatítica da Borborema possui uma área de cerca de $20.000 \mathrm{~km}^{2}$ e vem sendo estudada, explorada e pesquisada desde 1940. Entretanto, com o surgimento do APL de Pegmatitos RN/PB e de outros estudos, os especialistas passaram a considerá-la como uma área de grande importância econômica e social, com certo grau de vulnerabilidade e que precisava de apoio técnico.

Em função desse contexto abordado, instituições como a UFCG, o Centro de Tecnologia Mineral - CETEM, dentre outras, celebraram uma parceria, no âmbito do APL de Pegmatitos RN/PB, para a elaboração de projetos com o intuito de oferecer suporte técnico principalmente aos micros mineradores da região. O projeto inicial tinha como objetivos gerais a sensibilização e o incentivo ao associativismo/cooperativismo, a formalização dos processos produtivos, bem como o desenvolvimento de um plano de recuperação de áreas mineradas de caulim similar ao que foi desenvolvido nas áreas afetadas pelas olarias da região de Rio Claro, SP, (2012), o qual envolveu além do processo de formalização das atividades minerárias em áreas de extração ou lavra de argila, também apresentou orientação em relação à recuperação das áreas degradadas pela mineração da citada área.

Vale ressaltar, que nas áreas mineradas de caulim, situadas na Província Pegmatítica da Borborema, existem poucos planos de recuperação de áreas degradadas em execução, e as ações estabelecidas nos planos de recuperação de áreas mineradas não são executadas de forma mais adequada, devido à ausência de orientação técnica especializada e a carência de recursos financeiros (Sousa et al., 2018).

Neste trabalho, serão abordados aspectos importantes observados numa área minerada de caulim, no Sítio Galo Branco em Equador, RN, onde ocorre a maior parte da produção de caulim proveniente dos depósitos minerais existentes na Província Pegmatítica da Borborema. Em linhas gerais, a produção dessa matéria prima mineral é absorvida por vários segmentos industriais, entretanto, gera um volume elevado de resíduos que são lançados indiscriminadamente no solo, devido à baixa ineficiência no processo de beneficiamento mineral.

\subsection{Metodologia}

O procedimento metodológico desse estudo foi realizado mediante visitas técnicas à região pesquisada e feitas revisões da literatura existente, com a finalidade de ampliar o conhecimento sobre o tema em questão.

Conforme recomendações do Ministério das Minas e Energia, nos trabalhos de campo, foram observados os aspectos socioeconômicos, ambientais e técnicos envolvidos na atividade mineira, avaliando os seguintes aspectos: métodos de lavra, impactos ambientais, as condições de trabalho, as principais dificuldades para a formalização dos empreendimentos mineiros, a existência de planos de recuperação de áreas degradadas, dentre outros, mediante a interlocução com os atores sociais envolvidos com as operações de lavra e aproveitamento econômico do caulim.

Ainda durante este trabalho, foram realizadas ações para conscientizar os micros e pequenos mineradores com relação à necessidade da criação e formalização de uma cooperativa local. A partir dessas iniciativas foi possível constituir a Cooperativa dos Trabalhadores de Minério e Agricultura do Equador e do Seridó - COOTMAES, a partir de 2008, visando promover a organização social e produtiva dos trabalhadores atuantes nos segmentos de micro e pequena mineração e agricultura familiar, na mesorregião do Seridó, no âmbito do APL de Pegmatitos RN/PB.

Alguns dos resultados pretendidos com este estudo foram alcançados graças ao apoio das ações realizadas no âmbito do projeto intitulado "Integração de pesquisa e desenvolvimento tecnológico voltado para o aproveitamento racional e sustentável de minerais de pegmatitos e rochas de quartzitos", desenvolvido numa parceria da UFCG com o Centro de Tecnologia Mineral (CETEM), no período de 2013 a 2016. 
$\mathrm{Na}$ proposta de extração e aproveitamento do caulim de forma mais racional e menos rudimentar foi observado a inserção de um método de lavra a céu aberto com um planejamento de mina por meio de blocos, a adoção de um processo mecanizado com técnicas mais criteriosas de segurança no trabalho e o desenvolvimento de ações para a implantação do plano de recuperação de áreas degradadas pela atividade mineral de caulim.

Esse plano de recuperação consiste de uma técnica bem simples e que no momento está sendo adotada em processos de recuperação de áreas degradadas, provenientes da extração de calcário, na zona rural de Taperoá, PB. Essa metodologia está sendo difundida na região e consiste de procedimentos básicos para a recuperação da área minerada numa área piloto de 1 (um) hectare, onde a área plantada para a reabilitação ambiental será ampliada gradativamente, de acordo com o avanço das operações de lavra da substância mineral.

\section{Resultados e Discussões}

A geologia regional do território, onde estão inseridas as frentes de lavra de caulim, tem sido pesquisada desde 1910 e em todos os estudos realizados são admitidas a existência de duas unidades estratigráficas fundamentais (terrenos metassedimentares e complexos gnáissicos-migmatíticos-graníticos).

Para os especialistas, o território regional é constituído por formações de rochas pré-cambrianas do Neoproterozóico e Arqueano/Paleoproterozóico, definido por uma associação litoestratigráfica distribuída essencialmente nas unidades denominadas de Complexo Gnáissico-Migmatítico basal do Grupo Caicó, os metamorfitos do Grupo Seridó e as rochas filonianas (Sousa et al., 2018).

O caulim é uma argila constituída dentre outros minerais por caulinita e silicato hidratado de alumínio, proveniente do processo de intemperismo ou alteração dos feldspatos. Os depósitos de caulim encontrados nessa Província Mineral são em geral residuais/secundários e em algumas áreas estão encaixados na forma de veios na Formação Equador do Grupo Seridó.

No Sítio Galo Branco, onde foram realizados esses estudos, o caulim pode ser encontrado em veios de pegmatitos, bastante intemperizados, misturado com o feldspato em processo acentuado de alteração ou formando depósitos inteiros de dezenas de metros de espessura, onde essa alteração foi concluída, apresentando uma coloração bastante esbranquiçada. Esse depósito mineral compreende uma área de 13,12 ha, tendo como titular dos direitos minerários a COOTMAES, uma cooperativa de pequenos mineradores que recentemente obteve a renovação da licença ambiental de operação dessa área por mais seis anos, até 12/07/2027.

Nessa região, as operações de lavra dos minerais de pegmatitos, como o feldspato e o caulim, sempre foram realizadas por meio de galerias subterrâneas, construídas em condições inadequadas, rudimentares e sem acompanhamento de um técnico habilitado. Esses serviços de escavação do minério argiloso ocorriam de forma manual mediante o uso de picaretas e pás. Nessa etapa de extração, essas operações eram também desenvolvidas em condições de trabalho precárias, com o risco elevado de acidentes fatais e a possibilidade concreta dos mineradores contraírem doenças pulmonares, que afetam o sistema respiratório e são causadas pela inalação contínua de material particulado. Dentre essas doenças, a mais comum é a silicose, que pode causar invalidez e até provocar o aumento de óbitos na região (Rodriques, 2012).

Com base neste contexto, ficou evidenciado que esse método de lavra subterrânea utilizado para a extração do caulim não é o mais adequado, em virtude dos altos riscos para a saúde e a segurança do trabalhador. Sendo assim, tornou-se preponderante a escolha por um método de lavra mais racional, preferencialmente a céu aberto, que possibilite a economicidade da operação e menor exposição dos trabalhadores aos agentes de riscos dessa localidade. 
O método de lavra a céu aberto proposto deverá ser desenvolvido de forma mecanizada norteada por aspectos geotécnicos, com o uso de escavadeira substituindo as ferramentas manuais tradicionais (picaretas e pás) e com a tecnologia de lavra de bancadas acompanhando o delineamento topográfico do corpo mineralizado.

O minério extraído deverá ser transportado por caminhão caçamba terceirizado até as unidades de beneficiamento da região, conforme estabelece o planejamento prévio de lavra. Vale ressaltar, que obrigatoriamente todas as operações de lavra deverão ser desenvolvidas conforme os princípios de conservação ambiental, de forma a propiciar condições salubres de trabalho e melhorias efetivas na saúde dos trabalhadores.

Esse método foi escolhido sob o aspecto econômico, pois nessa área, o caulim situa-se próximo à superfície, está disposto em camadas sub-horizontais, com espessura do capeamento e do solo fértil de no máximo 1,0 m, propiciando o desenvolvimento das operações de lavra com mais segurança ao minerador. Com a adoção desse método de lavra, também deverá ocorrer a redução dos custos e dos impactos ambientais.

O pequeno volume de material estéril e de material orgânico do solo fértil será transportado por caminhão caçamba até um depósito de material controlado, situado em espaço adequadamente escolhido nos limites da área de abrangência do título minerário da COOTMAES e nas proximidades das frentes de lavra. Esse material poderá ser aplicado em vários usos, dentre eles na recuperação de áreas degradadas, na etapa de fechamento da mina. A Figura 2 mostra uma frente de lavra na área em estudo.

Figura 2 - Frente de lavra no Sítio Galo Branco, Equador, RN.

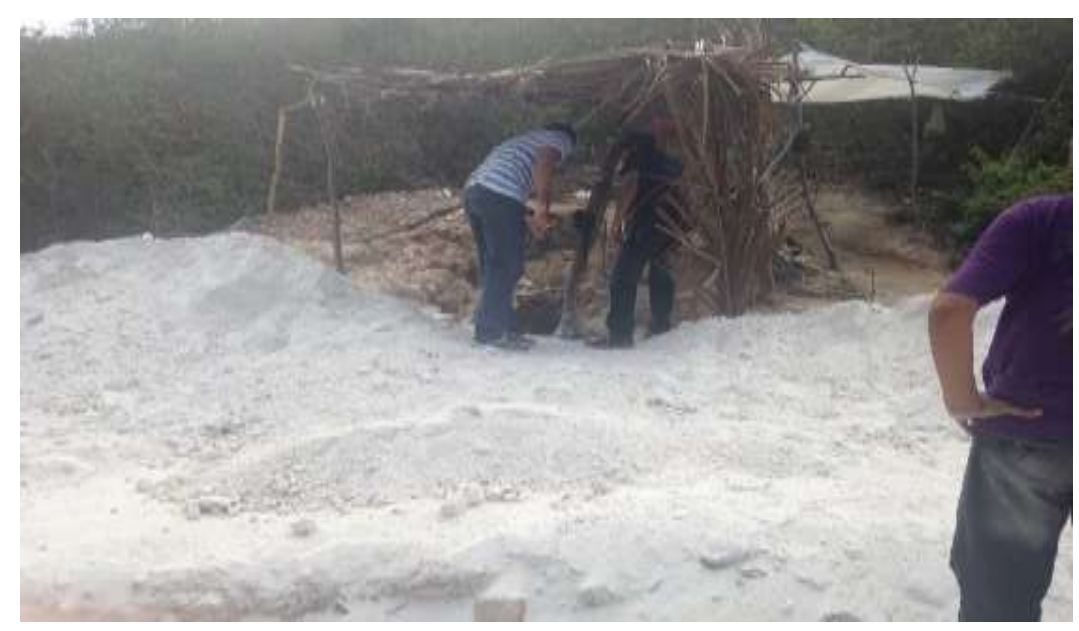

Fonte: Pereira (2016)

A análise dos impactos ambientais nesse estudo levou em consideração apenas as operações de lavra, e dessa forma foram observados apenas os impactos provenientes do processo de extração do caulim, que lançam um volume considerável de resíduos no solo, modificando a paisagem rural.

O impacto mais significativo causado pela extração de caulim é o que se refere à degradação visual da paisagem, ocasionada por esse descarte indiscriminado de resíduos, que provoca alterações significativas nos ecossistemas, compromete a evolução da fauna e da flora, causando inúmeros prejuízos às comunidades que habitam no entorno desses empreendimentos que lavram o caulim.

A paisagem das áreas onde estão situadas essas frentes de lavra é modificada numa extensão quilométrica. Os recursos hídricos têm seus percursos alterados, vegetações são extintas e animais se deslocam ou podem morrer devido aos 
impactos no solo, no ar e nas águas. A Figura 3 mostra a alteração da paisagem em virtude do descarte de resíduo do caulim extraído, nas proximidades do Sítio Galo Branco.

Figura 3 - Alteração da paisagem nas proximidades da área em estudo.

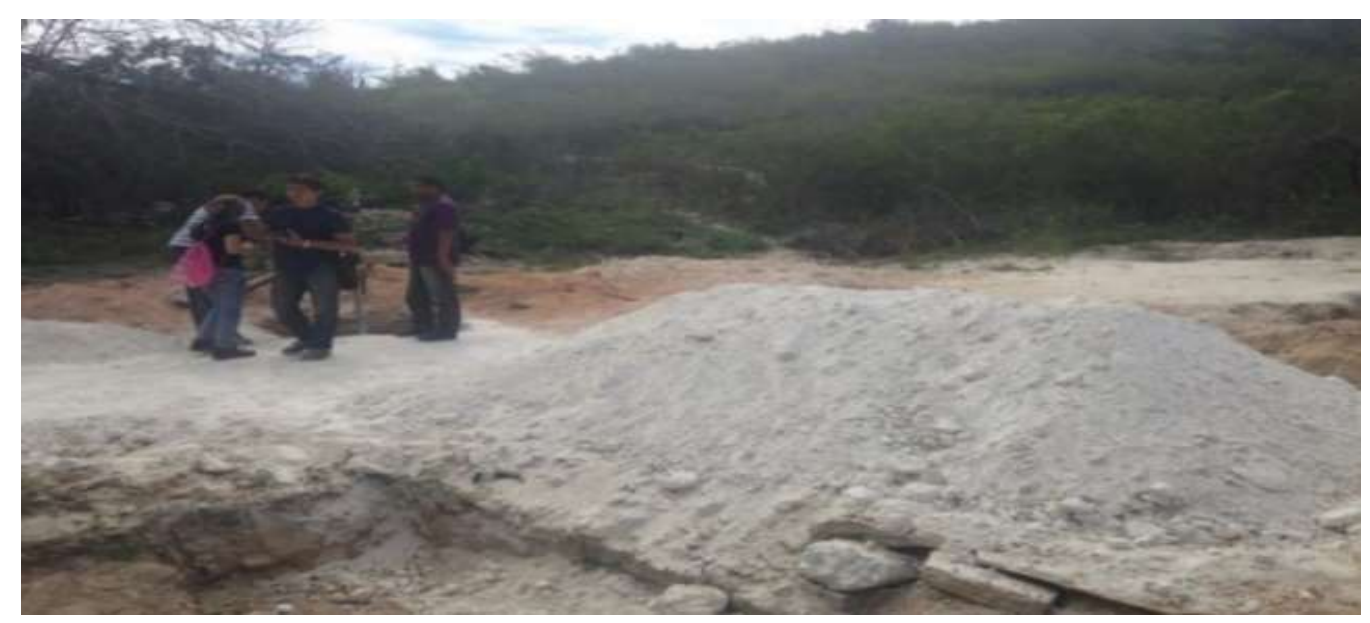

Fonte: Pereira (2016).

Uma exigência indispensável para que as operações de lavra e de recuperação de áreas degradadas, propostas nesse projeto, sejam bem sucedidas é que elas deverão ser implantadas cumprindo as condicionantes estabelecidas na licença ambiental e regularmente acompanhadas por profissionais habilitados.

Com base nas recomendações de Bitar (1997), o planejamento da recuperação da área degradada pela mineração de caulim, no Sítio Galo Branco será desenvolvido com observância aos seguintes princípios básicos: comprometimento e envolvimento dos associados da COOTMAES com os serviços de recuperação da área minerada; avaliação em detalhes da área degradada; definição transparente dos objetivos da recuperação e a definição do uso futuro da área minerada na fase de pósfechamento da mina, frente a outras possibilidades; elaboração de um plano de recuperação, abrangendo os métodos que serão empregados, descrição dos procedimentos que serão adotados, criação de um programa de monitoramento e manutenção das ações implantadas, dentre outros.

Outro ponto importante desse plano de recuperação, comumente também denominado pela legislação ambiental vigente de PRAD, é que, além da participação dos associados da COOTMAES, as ações a serem adotadas serão efetivadas progressivamente ouvindo as comunidades que habitam em localidades circunvizinhas a área minerada.

A área degradada pela mineração de caulim está inserida no Bioma Caatinga, que é considerado por cientistas e especialistas um dos biomas brasileiros mais alterados pelas atividades antrópicas. Conforme Trigueiro et al. (2009), a paisagem natural deste bioma tem perdido as suas características geoecológicas e algumas espécies da biota, devido à ocupação humana e às atividades socioeconômicas desenvolvidas nesse espaço geográfico.

Dentre essas atividades, são mencionadas: a extração ilegal de madeira para ser utilizada como fonte de energia em unidades industriais na região; o desmatamento da vegetação nativa para a realização de cultivos que adotam práticas de manejo inadequadas; a atividade mineral rudimentar e desordenada.

Conforme o MMA/SBF (2002), essas práticas inapropriadas são muitas vezes desenvolvidas de forma ilegal e têm contribuído para acelerar o processo de desertificação na Caatinga, a exemplo da região do Seridó, onde em várias situações o 
solo já perdeu a sua capacidade de regeneração e de manter a vegetação nativa, com efeitos negativos nos parâmetros dos recursos naturais responsáveis pelo equilíbrio dos ciclos biogeoquímicos e, por extensão, da biosfera como um todo.

De acordo com Prado (2003), o Bioma Caatinga apresenta características extremas em comparação aos outros biomas brasileiros. O clima na classificação de Koppen é do tipo BSh, sendo caracterizado por uma estação seca muito longa. A precipitação pluviométrica anual é irregular, muito baixa, variando de 300 a $800 \mathrm{~mm}$ anuais. A evaporação potencial é alta, com variação de 1500 a 2000 mm anuais. A temperatura média anual, a evapotranspiração e a radiação solar são bastante elevadas, por outro lado a umidade relativa do ar é muito baixa.

Para Velloso et al. (2002), a Caatinga apresenta uma variedade complexa de tipos de solos, desde solos rasos e pedregosos até solos profundos e arenosos, que em conjunto com a disponibilidade hídrica deverão definir os diferentes tipos de vegetação presentes neste Bioma. Vale ressaltar, que todas essas características, objetos dessas análises e discussões, foram consideradas para a elaboração da proposta para a recuperação da área degradada pela extração de caulim, no Sítio Galo Branco.

Chaer et al. (2011) destacam ainda que o uso de leguminosas arbóreas com capacidade de fixar N2 da atmosfera por intermédio da simbiose com N2 de bactérias fixadoras levaram à crença de que essas árvores podem ser usadas para vegetar solos altamente degradados e acelerar o processo de reabilitação. Em solos intensamente alterados, como os que estão presentes nas áreas de mineração, onde o teor de matéria orgânica tende a ser muito baixo, a introdução de espécies arbóreas, tende a aumentar significativamente os níveis de carbono no solo (Christopher et al., 2007). Essas afirmações desses autores corroboram para a utilização de algumas espécies arbóreas nativas no processo de recuperação das áreas mineradas e degradadas no Seridó.

Em resumo, conforme as recomendações de Sánchez et al. (2013), os trabalhos de recuperação da área minerada de caulim podem ser agrupadas: nas práticas edáficas que são relacionadas ao manejo e proteção do solo; nas práticas topográficas e geotécnicas que envolvem o remodelamento do terreno afetado pelas operações de mineração e visam a priori à estabilidade física das áreas recuperadas; nas práticas hídricas que propiciam à conservação da quantidade e da qualidade das águas superficiais e subterrâneas; e nas práticas ecológicas que são referentes ao manejo da biota, ou seja, da flora e da fauna, buscando estabelecer comunidades de espécies de vegetais e de animais nativos em áreas designadas na mina ou no seu entorno.

\section{Proposta de Recuperação da Área Minerada de Caulim}

A proposta do plano de recuperação de uma área degradada pela mineração de caulim, situada no Sítio Galo Branco, na zona rural do município do Equador, RN, tem por objetivo geral reativar os processos ecológicos que garantem a estabilidade ambiental dessa área degradada e contribuem para resgatar a sua capacidade de resiliência, visando o uso futuro da área minerada, na fase de pós-fechamento da mina, a princípio como área de lazer e recreação para a sociedade e, em especial, para as comunidades circunvizinhas ao empreendimento da COOTMAES.

A recuperação será um processo gradual, iniciado na fase de planejamento da etapa de lavra do minério e deverá prosseguir até depois de concluída as operações de lavra, quando forem estabelecidas as condições de equilíbrio de acordo com valores estéticos, ambientais e sociais já existentes no entorno da jazida.

A técnica ou método proposto nesse PRAD é bastante simples e será desenvolvida a princípio numa área piloto de 1 (um) hectare, já degradada no passado por outras atividades clandestinas e ilegais, antes da COOTMAES assumir a titularidade da área de abrangência outorgada e permitida pela Agência Nacional de Mineração - ANM. 
Nessa área piloto deverá ser realizado o plantio de espécies nativas florestais e arbóreas como craibeira, mulungu, baraúna, jucá, catingueira, aroeira, barriguda, ipê roxo; de espécies frutíferas nativas como umbuzeiro, juazeiro, pitanga, oitizeiro; e de espécies frutíferas exóticas adaptadas ao clima semiárido do Bioma Caatinga como acerola, caju, graviola, pinha, tamarindo, dentre outras.

Ressaltando, que essa técnica está sendo desenvolvida também de forma pioneira pela Mineração Jaramataia, numa área minerada de calcário, localizada na zona rural de Taperoá, PB.

A supressão vegetal será efetuada concomitantemente com os serviços de capeamento da frente de lavra utilizando trator de esteiras, carregadeira ou escavadeira. Nessa etapa, também serão removidos e armazenados fragmentos de rochas e a matéria orgânica do solo fértil para ser utilizada numa etapa posterior, para possibilitar de forma mais rápida a cobertura do solo da área em recuperação.

Neste processo de recuperação da área degradada pela mineração de caulim deverão ser utilizadas também outras estratégias como o isolamento da área por meio do cercamento para evitar o pisoteio de animais na vegetação em regeneração, e por meio da construção de aceiros para evitar a propagação de incêndios.

Outra estratégia importante a ser adotada será a produção de mudas de espécies florestais e frutíferas com qualidade, seguindo rigorosamente os padrões técnicos mais avançados para gerar mudas com boas condições fitossanitárias e bom desenvolvimento, para posterior plantio no campo em locais bem definidos. Lembrando que em áreas de taludes, esse plantio deverá ser realizado em curvas de nível, com o adequado acompanhamento topográfico.

Em resumo, o método de recuperação proposto para essa área piloto, degradada pela mineração de caulim, será desenvolvido de acordo com as seguintes etapas: marcação dos berços ou covas com piquetes, abertura dos berços, adubação de fundação no berço, plantio de mudas, controle de pragas e doenças, cobertura morta, adubação em cobertura, irrigação, realização do monitoramento e manutenção da área em processo de recuperação.

\section{Recomendações}

Criação de uma política pública efetiva, com a implantação imediata de medidas que fortaleçam essa atividade e de iniciativas inovadoras que possam garantir trabalho, renda e inclusão social aos trabalhadores que atuam nesse importante segmento econômico;

Criação e implantação de mecanismos de financiamento de projetos para micro e pequenos empreendimentos de mineração, como as cooperativas, de forma a promover verticalização das cadeias produtivas minerais, agregar valor aos produtos minerais lavrados e desenvolver as ações estabelecidas nos Planos de Recuperação de Áreas Degradadas - PRADs;

Implantação de um programa eficiente de disposição adequada e aproveitamento de resíduos gerados pela mineração, propiciando mais empregos, renda e garantia de um ambiente com mais qualidade de vida para as gerações futuras;

Criação de mecanismos para o fortalecimento e desenvolvimento de centros tecnológicos e inovação que incentivem e apoiem a inserção e difusão de tecnologias sustentáveis para os micros e pequenos empreendimentos de mineração.

\section{Conclusão}

Nesse estudo, ficou evidenciada a necessidade de apoio mais amplo, por parte das instituições competentes, para o desenvolvimento de projetos de mineração em bases sustentáveis, que contemplem principalmente a elaboração e a execução de planos de recuperação de áreas degradadas pela atividade mineral de micro e pequenos empreendimentos de mineração, 
localizados na Província Pegmatítica Borborema/Seridó, uma região com reconhecido potencial mineral, mas que ainda apresenta vulnerabilidades marcantes e desigualdades significativas.

Em muitas situações os pequenos empreendimentos mineiros dispõem de áreas formalizadas, de acesso a projetos inovadores de mineração e do suporte técnico científico de instituições, como a UFCG, mas não conseguem implantar e desenvolver esses projetos, devido às dificuldades impostas pelo sistema financeiro para o acesso ao crédito. Isto evidencia a necessidade urgente de implantação de uma política pública efetiva que atenda a esses anseios de décadas.

Como sugestões para trabalhos subsequentes, recomenda-se a análise de indicadores técnicos para estimar o quantitativo territorial de recuperação da área degradada após implantação das medidas sugeridas neste trabalho, além de um estudo comparativo da produtividade da lavra antes e após a implantação de planejamento mineiro e emprego de métodos de extração adequados ao integral aproveitamento mineral. Outro indicador de sucesso a ser analisado para esta atividade extrativista corresponde à verificação dos índices de acidentes laborais, cujo resultado esperado é a redução gradual e significativa destes sinistros, em função da interferência direta do responsável técnico pela operação do empreendimento mineiro.

\section{Agradecimentos}

Ao Ministério de Minas e Energia - MME;

Ao Ministério da Ciência, Tecnologia e Inovações - MCTI e;

Ao Programa de Entidades Associadas UFCG/CETEM, pelo apoio e financiamento de projetos na área pesquisada, no âmbito do APL de Pegmatitos RN/PB.

\section{Referências}

Almeida, I. C. S.; Ramos, A. J. S. \& Diniz, M. T. M. (2010). A problemática ambiental da extração de caulim no alto do chorão em Junco do Seridó/PB. www.agb.org.br/evento/download.php?idTrabalho=1605.

Bitar, O. Y. (1987). Avaliação da recuperação de áreas degradadas por mineração na Região Metropolitana de São Paulo. São Paulo. 185 p. Tese

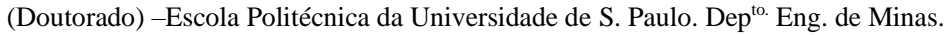

Chaer, G.M.; Resende, A.S.; Campello, E.F.C.; Faria S.M. \& Boddey R.M. (20011. Espécies de leguminosas fixadoras de nitrogênio para a recuperação de terras severamente degradadas no Brasil. Tree Physiol. 31: 139-49.https://doi.org/10.1093/treephys/tpq116;

Christopher S.F.; LAL R. (2007). O manejo do nitrogênio afeta o sequestro de carbono em solos agrícolas da América do Norte. Crit Rev Plant Sci.; 26: 4564. https://doi.org/10.1080/07352680601174830

CPRM - Companhia de Pesquisa de Recursos Minerais. Serviço Geológico do Brasil. (2005). Projeto Cadastro de Fontes de Abastecimento por Água Subterrânea. Paraíba. Diagnostico do Município de Equador. http://www.cprm.gov.br/rehi/atlas/rgnorte/relatorios/EQUA039.PDF.

Ferreira, G. C.; et al. (2012). Programa de apoio à legalização mineral de olarias da região de Rio Claro, São Paulo. REM: R. Esc. Minas, Ouro Preto, $65(1), 119-126$, jan. mar.

Gastauer, M.; et al. (2013). Reabilitação de terras de mina: abordagens ecológicas modernas para uma mineração mais sustentável. Instituto Tecnológico Vale, Rua Boaventura da Silva, 955, 66055-090, Nazaré, Belém, Brasil.

Harantová, L. et al. Desenvolvimento da comunidade microbiana durante a sucessão primária em áreas degradadas por atividades de mineração. (2017).

IBGE (Instituto de Brasileiro de Geografia e Estatística). Censo 2010. Recuperado de: http://cidades.ibge.gov.br/xtras/perfil.php?lang=\&codmun=240340.

MMA/SBF-Ministério do Meio Ambiente/Secretaria de Biodiversidades e Florestas. (2002). Avaliação e identificação de áreas e ações prioritárias para conservação, utilização sustentável e repartição dos benefícios da biodiversidade nos biomas brasileiros. Brasília: MMA/SBF, 404p.

Nascimento, I. B. (2002). Problemáticas ambientais e aplicações à saúde do trabalhador. O caso do garimpo de Esmeraldas em Campos Verdes - GO. Dissertação de Mestrado. Universidade de Brasília. Brasília.

Pereira, H. L. (2016). Aspectos socioeconômicos e ambientais da extração do caulim no Equador. RN. Trabalho de Final de Curso. Universidade Federal de Campina Grande. Campina Grande. 
Research, Society and Development, v. 10, n. 17, e219101724179, 2021 (CC BY 4.0) | ISSN 2525-3409 | DOI: http://dx.doi.org/10.33448/rsd-v10i17.24179

Prado, D. E. (2003). As Caatingas da América do Sul. In: Leal, I. R.; Tabarelli, M. \& Silva, J. M. C. (Eds). Ecologia e conservação da Caatinga. Ed. Universitária UFPE, Recife, pp. 03-74.

Resende, M. (2002). 500 anos de uso do solo no Brasil / Quintino Reis de Araújo (organizador). Capítulo 1. 605 pg- Ilhéus, Ba: Editus.

Rodrigues, C. C. \& Garcia, M. F. (2012). Garimpo: extrativismo e precariedade das relações sociais de produção no Seridó paraibano. http://www.proceedings.scielo.br/pdf/jtrab/n1/22.pdf

Sánchez, L. E.; Silva-Sánchez, S. S. \& Neri, A. C. (2013). Guia para o planejamento do fechamento da mina. - Brasília: Instituto Brasileiro de Mineração. 224 p.

Sousa, A. P. F. et al. (2018). A formalização da mineração em pequena escala no Seridó PB/RN e a sustentabilidade dessa atividade. In: CBMINA, IX. Belo Horizonte, $\mathrm{MG}$

Tavares, S. R. L. (2008). Curso de recuperação de áreas degradadas: a visão da Ciência do Solo no contexto do diagnóstico, manejo, indicadores de monitoramento e estratégias de recuperação - Sílvio Roberto T. de Lucena [et al.] -Dados eletrônicos. R.de Janeiro: Embrapa Solos,. 228 p.

Trigueiro, E. R. C.; Oliveira, V. P. V. \& Bezerra, C. L. F. (2009). Indicadores biofísicos e a dinâmica da degradação/desertificação no bioma Catinga: estudo de caso no município de Tauá, Ceará. Revista Eletrônica do Prodema, 3, 62-82.

Velloso, A. L.; Sampaio, E. V. S. B. \& Pareyn, F. G. C (Eds). (2002). Eco regiões: propostas para o bioma Caatinga. Recife: Associação Plantas do Nordeste; Instituto de Conservação Ambiental-The Nature Conservancy do Brasil, 76p. 